\title{
A Rare Case of a Large Basal Cell Carcinoma of the Vulva
}

\section{Christina Stefanaki ${ }^{*}$, Leonidas Chardalias ${ }^{2}$, Konstantina Fragia ${ }^{3}$, Dimitrios Rigopoulos ${ }^{1}$, Alexander Stratigos ${ }^{1}$}

\author{
${ }^{1}$ First Dermatology Department, Andreas Sygros University Skin Hospital, Athens, Greece \\ ${ }^{2}$ Surgery Clinic, Areteio University Hospital, Athens, Greece \\ ${ }^{3}$ Histo-Bio Pathology Diagnostic Center, Athens, Greece \\ Email: ${ }^{*}$ cstefana@otenet.gr
}

How to cite this paper: Stefanaki, C., Chardalias, L., Fragia, K., Rigopoulos, D. and Stratigos, A. (2019) A Rare Case of a Large Basal Cell Carcinoma of the Vulva. Open Journal of Obstetrics and Gynecology, 9, 1439-1442.

https://doi.org/10.4236/ojog.2019.911139

Received: September 30, 2019

Accepted: November 2, 2019

Published: November 5, 2019

Copyright $\odot 2019$ by author(s) and Scientific Research Publishing Inc. This work is licensed under the Creative Commons Attribution International License (CC BY 4.0).

http://creativecommons.org/licenses/by/4.0/

\begin{abstract}
We present an interesting and unusual case of a $5 \mathrm{~cm}$ well-demarcated erosive plaque on the labia minora, extending to the vagina in an 85-year-old woman, causing pain and discomfort for 2 years. The patient was treated several times with topical and systemic anti-fungals without benefit. Histopathology revealed a typical superficial spreading basal cell carcinoma (BCC) and the patient was referred to a gynecologist for surgical excision. Our case is an alert of BCCs arising on the genital area because they are rare and patients usually present with large lesions, as they do not seek medical attention for what they consider simple irritation. Physicians easily misdiagnose these cancers as inflammatory or infectious dermatoses.
\end{abstract}

\section{Keywords}

Basal Cell Carcinoma, BCC, Genitalia, Differential Diagnosis

\section{Introduction}

Although BCC is the most common skin malignancy accounting for $80 \%$ of all non-melanoma skin cancers, it rarely arises from the genitalia [1]. The genitalia as a primary site of BCC is very rare accounting for $<1 \%$ of all BCCs and only 250 cases have been reported in the literature [2]. In general, vulvar BCCs represent $2 \%-7 \%$ of vulvar malignancies, arising usually in elderly women [3].

\section{Case Report}

An 85-year-old female patient presented with vulvar pain and discomfort for the past 2 years. She had several courses prescribed by private practice based gyne- 
cologists of anti-fungal medications including fluconazole and itraconazole combined with topical anti-fungals, without any improvement. The patient suffered only from arrhythmia and was on metoprolol. On clinical examination a large 5 $\mathrm{cm}$ max diameter, well demarcated erosive plaque could be detected involving the labia minora and extending to the vagina (Figure 1). A speculum was not inserted to delineate the depth of extension to the vagina. Inguinal lymph nodes were not palpable. Dermoscopy of the skin lesion did not reveal any specific features as only erythema and few erosions could be detected. A punch biopsy was taken and histopathology revealed a typical superficial spreading basal cell carcinoma BCC (Figure 2). Ultrasound of the inguinal lymph nodes did not reveal any abnormal lymph nodes. The patient was referred to a gynecologist for surgical excision.

\section{Discussion}

BCCS of the vulva are poorly studied and reported because they are rare. Although the etiology is unknown chronic vulvar irritation, radiation and exposure to arsenic are known risk factors [4] [5]. The most common presenting symptom is pain, ulceration, bleeding and pruritus [2]. The clinical picture of vulvar BCC is non-specific and exophytic, pendunculated, ulcerated, nodular and pigmented lesions have been described [6]. Usually the tumors are quite large at diagnosis possibly because patients do not seek medical attention for what they

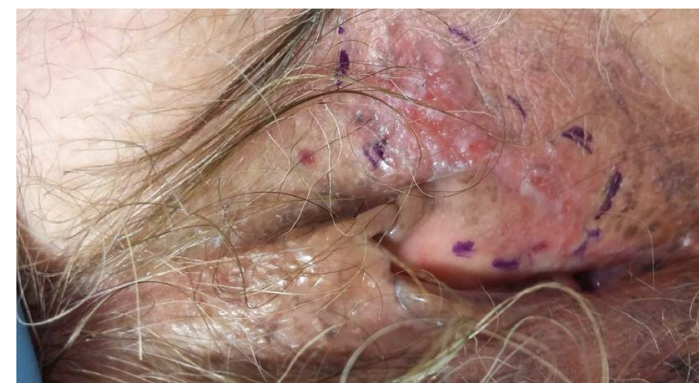

Figure 1. A large ulcerated lesion measuring $5 \mathrm{~cm}$ on the labia minora of an elderly woman.

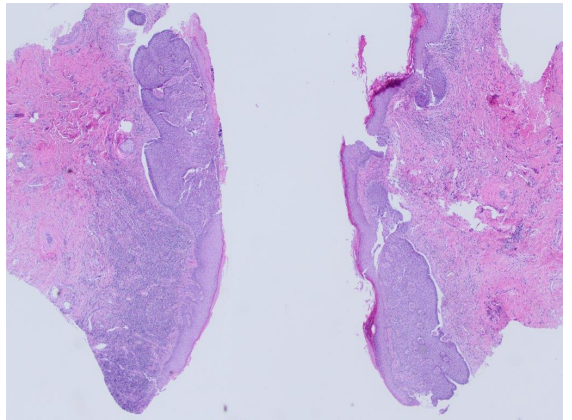

(a)

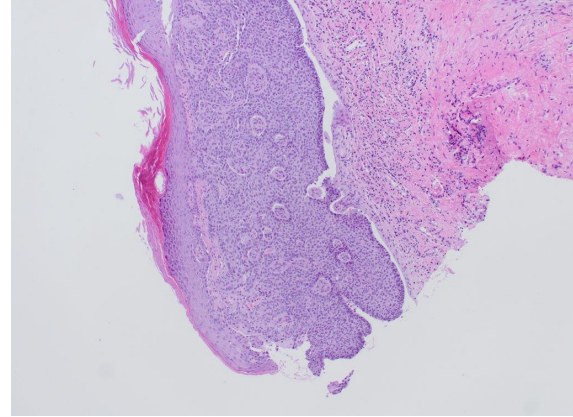

(b)

Figure 2. (a) Nests of neoplastic cells attached to the epidermis with peripheral palisading and detachment of the surrounding dermis. Normal epidermis is observed between the nests. (b) Nests of neoplastic cells with peripheral palisading (higher magnification). 
consider simple irritation or because physicians easily misdiagnose these cancers as inflammatory or infectious dermatoses [7]. Differential diagnosis based on the clinical findings includes extramammary Paget's disease, Bowen's disease, lichen simplex chronicus and lichen sclerosus et atrophicus. Histological heterogeneity characterizes BCC of the vulva and different histologic types can be identified including superficial spreading, nodular, infiltrative, micronodular, basosquamous and fibroepithelioma of pinkus [7]. The treatment of choice is wide surgical excision as the vulva is a high-risk area for recurrence and recurrence rates as high as $20 \%$ have been reported [8]. Other treatment options for superficial spreading tumors include cryosurgery and imiquimod, although tolerance of those treatments in this body area could understandably be poor. Usually, the tumor has a favorable prognosis, however metastatic vulvar BCCs have been reported [9] [10]. In metastatic vulvar BCCs the duration of symptoms usually is long, the patients may present with bloody vaginal or vulvar discharge, in all patients a deep infiltrative or large primary tumor can be detected and usually a more aggressive histologic subtype [8].

Although our case is interesting and informative, the conclusions drawn are limited given that the extent of the lesion in the vagina was not delineated and that is a single case report and not a presentation of case series. Moreover, we don't have a follow up of the patent after surgery and no information is available about surgery margins, surgical technique and possible recurrence.

In conclusion, any chronic, persistent lesion in the vulvar region, especially in advanced ages should be subjected to histological examination. Vulvar BCC might be misdiagnosed because of the similarity of other diseases and the clinician should pay attention to avoid a neglected case.

\section{Conflicts of Interest}

The authors declare no conflicts of interest regarding the publication of this paper.

\section{References}

[1] Rubin, A.I., Chen, E.H. and Ratner, D. (2005) Basal-Cell Carcinoma. The New England Journal of Medicine, 353, 2262-2269. https://doi.org/10.1056/NEJMra044151

[2] Fleury, A.C., Junkins-Hopkins, J.M. and Diaz-Montes, T. (2011) Vulvar Basal Cell Carcinoma in a 20-Year-Old: Case Report and Review of the Literature. Gynecologic Oncology Case Reports, 2, 26-27. https://doi.org/10.1016/j.gynor.2011.11.005

[3] Pleunis, N., Schuurman, M.S., Van Rossum, M.M., Bultend, J., Massugera, L.F., De Hullu, J.A., et al. (2016) Rare Vulvar Malignancies; Incidence, Treatment and Survival in the Netherlands. Gynecologic Oncology, 142, 440-445. https://doi.org/10.1016/j.ygyno.2016.04.021

[4] Piura, B., Rabinovic, A. and Dgani, R. (1999) Basal Cell Carcinoma of the Vulva. Journal of Surgical Oncology, 70, 172-176. https://doi.org/10.1002/(SICI)1096-9098(199903)70:3<172::AID-JSO5>3.0.CO;2-I

[5] Benedet, J.L., Miller, D.M., Ehlen, T.G. and Bertrand, M.A. (1997) Basal Cell Carcinoma of the Vulva: Clinical Features and Treatment Results in 28 Patients. Obstetrics 
\& Gynecology, 90, 765-768. https://doi.org/10.1016/S0029-7844(97)00416-X

[6] Pisani, C., Poggiali, S., La De Padova, Andreasi, A. and Bilenchi, R. (2006) Basal Cell Carcinoma of the Vulva. Journal of the European Academy of Dermatology and Venereology, 20, 446-448. https://doi.org/10.1111/j.1468-3083.2006.01456.x

[7] Gibson, G.E. and Ahmed, I. (2001) Perianal and Genital Basal Cell Carcinoma: A Clinicopathologic Review of 51 Cases. Journal of the American Academy of Dermatology, 45, 68-71. https://doi.org/10.1067/mjd.2001.114588

[8] Milayim, N., Silver, D.F., Ocal, I. and Babalola, E. (2002) Vulvar Basal Cell Carcinoma: Two Unusual Presentations and Review of the Literature. Gynecologic Oncology, 85, 532-537. https://doi.org/10.1006/gyno.2001.6582

[9] Watson, G.A., Kelly, D., Prior, L., Stanley, E., MacEneaney, O., Walsh, T. and Kelly, C.M. (2016) An Unusual case of Basal Cell Carcinoma of the Vulva with Lung Metastases. Gynecologic Oncology Reports, 18, 32-35. https://doi.org/10.1016/j.gore.2016.10.005

[10] Winkelmann, S.E. and Liorens, A.S. (1990) Metastatic Basal Cell Carcinoma of the Vulva. Gynecologic Oncology, 38, 138-140.

https://doi.org/10.1016/0090-8258(90)90027-I 